\title{
Venezuela: Política Exterior y Rentismo
}

\author{
Carlos A. Romero \\ Claudia Curiel(*)
}

\begin{abstract}
Resumen: En este trabajo se busca analizar la relación entre la política exterior del gobierno bolivariano del presidente Chávez y la manera como se hace la cooperación internacional. Se parte de la hipótesis que el rentismo, categoria para el estudio de la economía interna, en cuanto a la manera de otorgar ayuda económica sin retorno, se ha trasladado en el caso de Venezuela a la cooperación que ejerce el país con algunas naciones, a través de donaciones, subsidios y condiciones especiales no económica ni comerciales, es decir, bajo transferencias no retornables.
\end{abstract}

Palabras-clave: Venezuela, Política Exterior, Chávez, Rentismo.

Abstract: This paper analyzes the relationship between the foreign policy of the Bolivarian government of President Chávez and how it is its international cooperation. It is assumed that rentism, category for the study of the domestic economy, in how to provide aid without return, has moved in the case of Venezuela in a kind of international cooperation through donations, grants and special conditions which are not economic or commercial, under non-returnable transfers.

Keywords: Venezuela, Foreign Policy, Chávez, Rentism.

(*) Carlos A. Romero es un politólogo venezolano, Doctor en Ciencias Políticas y profesor titular en la Universidad Central de Venezuela. E-mail: romecan53@hotmail.com. Claudia Curiel es economista venezolana y consultora internacional en el tema de la regulación económica. E-mail: ccuriel6@yahoo.com. Recebido em 23.2.09 e aceito em 28.4.09. 


\section{INTRODUCCIÓN}

La comprensión del reciente fenómeno político venezolano se ha hecho una difícil tarea para los analistas que han tratado de estudiar un caso observado previamente con cierto desdén. Para algunos, en Venezuela no pasaba nada y por lo tanto no era un tema importante para saber por donde iba América Latina. Para otros, la configuración política venezolana se consideraba como un modelo sui-generis difícil de clasificar (KARL, 1997). En nuestros días, Venezuela ahora parece un "Dèjà Vu". Es decir todo es diferente, pero, a la vez, se da la sensación de que lo actual se ha experimentado antes y que todo parece familiar.

Al superarse los problemas de formación de un sistema que dejaba atrás la dictadura militar y que desarrollaba un régimen democrático y constitucional, Venezuela comenzó a observarse como un caso exitoso de transición política (REY, 1989; KORNBLITH, 1997). Se trató de definir al sistema político venezolano (desde ahora, SPV) como un sistema estable, dada la presencia de un sistema populista de conciliación de elites, de un Estado poderoso con un ingreso petrolero recurrente y con una alta capacidad de distribución de la renta petrolera (KARL, 1997). A esto se añadía, la tesis del control civil sobre las Fuerzas Armadas y sobre otros grupos de presión, gracias al dominio que ejercieron sobre ellas los partidos políticos mayoritarios, Acción Democrática (AD) y el partido socialcristiano COPEI (LEVINE, 1973; REY, 1989).

Sin embargo, el SPV dio signos de su agotamiento a fines de la década de los setenta. El esquema de relación clientelar basado en la renta petrolera, conocido como el "rentismo", la creciente disparidad en los ingresos entre sectores sociales, la aparición de una inflación alta, de una deuda externa considerable y de una tasa de cambio negativa conjuntamente con la reducción de los ingresos petroleros, se unieron a situaciones políticas especificas, como la pérdida del control de la sociedad por Ad y Copi, el crecimiento de la protesta popular y el desarrollo de posiciones antipartidistas, provenientes de sectores que impulsaban un pensamiento liberal, o de sectores radicales con una base ideológica marxista (ROMERO, 2006).

En el campo académico, el cuestionamiento de la visión optimista sobre el SPV comenzó a jugar un papel significativo. Si bien es cierto que se habían dado unos estudios pioneros que ponían en duda los factores explicativos del sostenimiento del SPV, éstos no tuvieron el impacto generado por numerosos libros y artículos que desde la década de los ochenta del siglo pasado pusieron en duda el análisis político dominante en los estudios sobre Venezuela, es decir, aquel que sostenía la tesis de una estabilidad política lograda por el "Pacto de Punto Fijo" (SILVA MICHELENA, 1967; NAIM, PIÑANGO, 1984).

Por otro lado, se alertó sobre el hiper-crecimiento del gasto público y la exagerada dependencia presupuestaria de los ingresos petroleros, la incesante corrupción administrativa, la carencia de una verdadera apertura democrática, y el deterioro de las relaciones cívico-militares (REY, 1991; LEVINE; 1973, KORNBLITH, 1997; DIAMINT, 2005).

De igual forma, se puso en duda la idea prevaleciente en el debate público sobre que la política exterior de Venezuela reflejaba el consenso alcanzado en la vida política interna. 
De esta manera surgieron importantes voces críticas que señalaban que la política exterior se estaba sobredimensionando con un hiper-activismo voraz, y una falta de consenso en los temas exteriores, como los relativos a las relaciones con Cuba y con Estados Unidos, los temas territoriales y el comercio exterior.

Basta mencionar tres acontecimientos históricos que no concordaron con una visión optimista del llamado consenso en política exterior: 1) Cuando el presidente Rómulo Betancourt decidió votar, en el año 1960, a favor de la resolución de la OEA en donde se condenaba la supuesta injerencia de la Unión Soviética en los asuntos internos latinoamericanos y en Cuba, el ministro de Relaciones Exteriores de la coalición gubernamental renunció al cargo y meses más tarde, su partido, Unión Republicana Democrática, URD, se retiró del Gobierno y del Pacto de Punto Fijo. 2) En 1969, el Gobierno de Rafael Caldera no obtuvo el respaldo empresarial privado venezolano para que Venezuela entrara en la Junta del Acuerdo de Cartagena (hoy, Comunidad Andina de Naciones) y el Presidente venezolano tuvo que negociar con ese sector para que finalmente se aceptara la incorporación del país en el año 1973. 3) En otra ocasión, el presidente Luís Herrera Campíns presentó al país en 1980, una posible solución al contencioso sostenido con Colombia sobre la delimitación de áreas marinas y submarinas, lo que fue rechazado por el estamento militar y una parte importante de la opinión publica venezolana, retirándose así esa propuesta (REY, 1983; ROMERO, 2006; CARDOZO, 1998).

Carlos Andrés Pérez fue elegido nuevamente Presidente de la República para el período 1989-1994 e inmediatamente después a su llegada al poder, aplicó la receta del Consenso de Washington. Esa terapia de shock fue un detonante para que se desarrollara un fuerte estallido social en febrero de 1989, dos intentos de golpe militar en 1992 y la salida del propio presidente Pérez de su cargo en mayo de 1993, antes de esperar el término de su mandato, en medio de una crisis de legitimidad del SPV, y su reemplazo por dos presidentes interinos: Octavio Lepage (del 21 mayo al 5 de junio de 1993) y Ramón J. Velásquez (del 5 de junio de 1993 al 2 de febrero de 1994).

El presidente Velásquez, a su vez, le entregó el poder al Rafael Caldera, quien ya había sido presidente de Venezuela en el periodo 1969-1974 y quien había ganado las elecciones de diciembre de 1993 con la bandera de recuperar el buen desenvolvimiento del SPV si se retornaba a sus bases originales.

Hugo Chávez, oficial retirado del Ejército venezolano, quien había participado en el intento de golpe de 1992, procesado, indultado y retirado de la institución castrense en 1994 y quien en un principio se negó a participar en la lucha electoral, reconoció en el año de 1997 que se daban las condiciones para llegar al poder por la vía electoral. Chávez ganó las elecciones de diciembre de 1998 obteniendo un 56 por ciento de los votos, con una plataforma populista y con una alianza heterogénea que lo llevó a la presidencia de la Nación en enero de 1999, ofreciendo un cambio de raíz en la vida política venezolana y desde un discurso radical (el candidato opositor más importante, Henrique Salas Römer, presentó un programa de corte liberal y obtuvo un 40 por ciento de los votos).

De manera metafórica, se puede decir que, Carlos Andrés Pérez había ofrecido una medicina nueva para mejorar el enfermo, vale decir el SPV, Rafael Caldera quiso regresar 
a una vieja medicina y Hugo Chávez determinó que el problema no eran las medicinas sino que había que operar al paciente.

Tan pronto Hugo Chávez llegó al poder en Venezuela por la vía electoral, planteó una fórmula diferente para el SPV en donde la consulta y la idea de unas reglas de juego consensuales fueron a ser remplazadas por la identificación del Gobierno con la tesis de una voluntad general que rechazaba la unanimidad, algo que había caracterizado el pasado democrático venezolano reciente (KORNBLITH, 2007).

Hugo Chávez ganó las elecciones en 1998 con la idea de dividir a la historia democrática venezolana en dos períodos, la Cuarta y la Quinta repúblicas, e inició un proceso transformador de raíz, en un país que desde entonces ha tenido una nueva Politeia, con un nuevo modelo político, un desplazamiento de élites, un nuevo actor primus inter pares (el presidente Chávez); y una serie de nuevas propuestas sobre el futuro de las relaciones entre el Estado y la sociedad.

En este marco, se puede analizar el proceso chavista bajo la idea de que éste ha transitado por tres etapas. La primera va desde el año de 1999 hasta el año 2000, la cual se podría calificar como una etapa de transición hacia un nuevo modelo político y económico de corte populista democrático y bajo la rectoría de un proceso constituyente, el cual dio lugar a la Constitución de 1999, las elecciones presidenciales de julio de 2000 y la relegitimación de los poderes públicos en esa misma fecha.

Una segunda etapa, transcurre del año 2000 al año 2004 y se puede clasificar como una etapa de fundamentación del nuevo modelo, en medio de un proceso plagado de inestabilidad e incertidumbre originado por el choque entre el Gobierno y la alianza oficialista en contra de la oposición, y que tuvo como puntos de inflexión el golpe de Estado en contra del presidente Chávez en abril de 2002 y la celebración del Referéndum Revocatorio Presidencial en agosto de 2004 (considerado este instrumento como la salida política, democrática y constitucional a la crisis planteada durante esos años).

Una tercera etapa comenzó ese mismo año 2004 y la podemos definir como un momento de ejecución de un modelo radical, con una orientación más definida, estatista y de ruptura con el pasado, la cual se bautizó como el "Socialismo del siglo XXI".

En el año 2006, y en ocasión de celebrarse unas nuevas elecciones presidenciales en Venezuela, el presidente Chávez llevó su oferta programática hacia la concreción de un modelo sin las ambigüedades anteriores, en lo que algunos analistas pro-gobierno llaman, de acuerdo al pensamiento marxista tradicional, el paso de una etapa nacional liberadora y reformista a una etapa de pleno socialismo, que desde el 2007 tiene como norte la ejecución del Socialismo del siglo XXI; del poder comunal y de la reforma constitucional (COOPEDGE, 2005; KORMBLITH, 2007).

Desde el punto de vista de la política exterior y a partir del año de 1999, el gobierno del presidente Hugo Chávez comenzó a cambiar sus fundamentos. Con base en tres etapas que corresponden a los cambios internos, 1999-2000, 2000-2004 y 2004 hasta nuestros días, la diplomacia venezolana ha desarrollado una contra-agenda dentro de una combinación de temas tradicionales y novedosos: la utilización del petróleo como el instrumento principal de participación en el escenario mundial y hemisférico; el activismo internacional 
del país; la promoción de un nuevo modelo político: la democracia participativa y protagónica; el lanzamiento de un nuevo modelo económico: el desarrollo endógeno y la propuesta del Socialismo del siglo XXI; la promulgación de una nueva Ley de Servicio Exterior; la ideologización y partidización del servicio exterior y la generación de una diplomacia "social" con el respaldo a diversas organizaciones políticas, sociales y culturales anti-globales en los ámbitos internacional y regional.

De igual modo, el proceso político venezolano se ha fundamentado en los medios de comunicación social, internacionales y regionales, y tanto el gobierno como los sectores políticos que lo apoyan y la misma oposición venezolana han hecho del plano mundial un escenario fundamental de sus actuaciones y diferencias. Así, "Bajo su amparo, las relaciones internacionales de Venezuela se han tornado más amplias y diversas en cuanto a lo geográfico y más intensas con grupos no gubernamentales de lo que son con los gobiernos de otras naciones" (NAIM, 2005).

En este artículo se analiza los fundamentos domésticos e internacionales que dan lugar a esa nueva política exterior, el papel de la renta petrolera en ella y las proyecciones de esa política.

\section{UNA POLÍTICA EXTERIOR PARA EL CONSENSO}

A partir del año 1958, Venezuela jugó con la idea de ser un país occidental, con un pasado colonial hispánico, situado en América Latina y con tres fuertes identidades: país democrático, petrolero y con amplias relaciones con Estados Unidos. De la misma manera se originó un estilo diplomático basado en una política exterior con un fuerte presidencialismo, un activismo internacional, una relación positiva con el ambiente externo y un consenso sobre los fines e instrumentos de la política exterior. Sobre este perfil, se conformaron una serie de objetivos formales y reales.

La política exterior de Venezuela tuvo, desde el año 1958 hasta 1999, un marco legal institucional que fue la Constitución Nacional de 1961. Este marco legal imprimió un estilo diplomático basado en un conjunto de principios generales expresados en el preámbulo de la Carta Magna: el carácter pacífico del país, la búsqueda de la integración económica, el deber de cooperar internacionalmente, la promoción de la democracia y otros conceptos emanados de la Carta de las Naciones Unidas; la discrecionalidad del presidente de la República en el ámbito de la política exterior; el carácter petrolero de la nación, pero en función de promotor de una economía diversificada, y el desarrollo de varias identidades para una política exterior considerada a su vez como: andina, caribeña, hemisférica, tercermundista y amazónica (REY, 1983).

De 1958 a 1967, la diplomacia venezolana se concentró en la búsqueda de la consolidación democrática en el país y en la región, en impulsar el proceso de sustitución de importaciones, en promover la creación de la OPEP (sin el sacrificio de perder una relación petrolera especial con Estados Unidos) para buscar mejores precios petroleros, en impulsar la Doctrina Betancourt (orientada al no reconocimiento de gobiernos de fuerza producto del derrocamiento de un gobierno civil, que surgieran en América Latina y el Caribe) y en la defensa de la seguridad regional y nacional frente a la llamada injerencia cubano-soviética. 
De 1967 hasta 1980, la política exterior del país se formuló con el fin de respaldar la estabilidad democrática de la experiencia venezolana, en abrir la agenda exterior hacia los temas económicos de la integración - con participación en la ALALC (hoy ALADI), en el Pacto Andino (hoy Comunidad Andina de Naciones) y de forma plena en la OPEP y para retomar las negociaciones en torno a los problemas fronterizos.

De 1982 a 1988, la política exterior de Venezuela se vio limitada en su extensión, debido a la caída de los precios petroleros, el creciente peso de la deuda externa y la aparición de tensiones políticas internas y no consensuales en la política exterior, concentrándose así en una actuación regional de apoyo a las opciones pacíficas regionales, como fue el caso del Grupo de Contadora, y el fortalecimiento de dirigentes y partidos del centro democrático (CARDOZO, 1998).

Desde 1989 hasta 1999, dada la convergencia del impacto de los cambios globales con el deterioro de la situación política interna, las relaciones internacionales de Venezuela se caracterizaron por ser más complejas y variadas. Durante la segunda presidencia de Carlos Andrés Pérez (1989-1993) se adoptaron las políticas en boga dentro del Fondo Monetario Internacional (FMI) y el Banco Mundial, (aunque se originó una profunda reacción negativa en la población), y se retomó el activismo de la política exterior de Venezuela, sin sacrificar las múltiples identidades de Venezuela en el exterior. De hecho, el presidente Carlos Andrés Pérez volvió a practicar la política de las "dos manos"; vale decir, osciló entre un internacionalismo más "tercermundista" y orientado hacia los temas comerciales, de cooperación Norte-Sur y de integración, y un regionalismo hemisférico más comprometido con la apertura económica y la democratización. Esto dio lugar a una política exterior hiperactiva que provocó mucha irritación en Venezuela, lo que se constituyó en una de las principales causas que provocaron los dos intentos de golpe de Estado en 1992 (CARDOZO, 1998).

Con la salida de Pérez de la presidencia de la República, en mayo de 1993, y la llegada de los presidentes interinos, la política exterior de Venezuela se concentró en lograr el apoyo de Washington y de América Latina a la democracia venezolana y a la convocatoria a las elecciones presidenciales de diciembre de 1993.

Rafael Caldera llegó por segunda vez a la presidencia de la República en 1994. Si bien desde el punto de vista estratégico no hubo ninguna discrepancia importante que permitiera pensar que el gobierno del presidente Caldera iba hacia la sumisión o el enfrentamiento con Estados Unidos, sí hubo a nivel táctico algunas discrepancias que enfriaron las relaciones. El Gobierno del presidente Caldera observó con escepticismo todo el proceso del ALCA y la apertura económica defendida por Washington (de hecho promulgó en sus dos primeros años una política económica estatista y de controles) (CARDOZO, 2006).

\section{UNA POLÍTICA EXTERIOR PARA LA MAYORÍA}

Si algo se destaca en los análisis recientes sobre la situación venezolana es el rol que juega la política exterior en la dinámica política del país. Desde un punto de vista mundial, el presidente Chávez se ha convertido en los últimos años en una especie de enfant terribl que ha venido tejiendo una diplomacia hiperactiva y llamativa. Sus querellas con Estados 
Unidos, su acercamiento al régimen cubano y a otros gobiernos vistos con reservas por Estados Unidos (Belorus, Irán, Rusia, China), la promoción de la OPEP como organización política, su clamor por un mundo multipolar, su creencia en la soberanía nacional absoluta y su apoyo a la revolución continental despiertan muchas simpatías en sectores sociales e intelectuales de América Latina, pero al mismo tiempo, generan algunas reservas (ROMERO, 2006; CARDOZO, 2006).

El gobierno del presidente Chávez revivió en el país la visión estructuralista y anticapitalista que genera las tesis del desarrollo endógeno, del fortalecimiento del Estado como instrumento central de desarrollo, y de la profundización del Estado socialista, formándose así un paquete ideológico "anti-occidental" configurado en una visión del mundo basada en las ideas de la rivalidad entre el centro y la periferia y en la lucha antiimperialista.

Lo anterior está aunado a la condición petrolera del país, de la cual se estima, es su verdadera ventaja comparativa. Es por ello que el activismo histórico de Venezuela en el plano internacional, se reafirma con este gobierno, pero de manera más definida. Ya no se pretende jugar con las tesis de las "múltiples identidades", sino más bien se refuerza la militancia venezolana en el tercermundismo, en el Sur, en el seno de la OPEP, en las Naciones Unidas y con las naciones disidentes del orden internacional.

En el plano de las relaciones interamericanas, el gobierno de Chávez ha tenido una postura controversial al oponerse a las posiciones estadounidenses en el seno de la OEA; en referencia al papel del organismo como garante de la democracia en América Latina y el Caribe, en materia de promoción de la democracia y de los derechos humanos y en el papel de las misiones observadoras y de las organizaciones no gubernamentales en los procesos electorales en la región.

Venezuela ha tenido una política exterior con Colombia concentrada en las reservas que tiene el gobierno de Chávez sobre la así llamada orientación pro-estadounidense del Gobierno del presidente Uribe, el apoyo colombiano al ALCA, las consecuencias para las relaciones entre los dos países de la eventual firma del tratado bilateral de libre comercio entre Colombia y Estados Unidos, en la salida de Venezuela de la Comunidad Andina de Naciones y en las diferencias sobre la violencia en Colombia y el proceso de pacificación en ese país. El país de al lado desea venderle a Venezuela sus bienes y servicios, pero Bogotá conoce de las ambigiuedades de Caracas con la guerrilla de ese país y de la apología del Gobierno venezolano con las FARC.

El hecho que al presidente Chávez se le pidiera en el 2007 que interviniera como mediador en las negociaciones entre el Gobierno de Uribe y la FARC se vio con buenos ojos en Colombia. Dada la situación de estancamiento de las negociaciones, se apoyó la gestión del presidente Chávez, dentro de las reservas de Caracas sobre que el Gobierno de Uribe cambiara de posición (enfrentar militarmente a la FARC y no permitir una zona de distensión), al igual que la conducta de la FARC (pedir un zona de distensión y liberar a dirigentes y miembros de la FARC presos). Esta iniciativa no prosperó.

En cuanto a Cuba, se ha generado una relación especial favorable entre los dos países. El presidente Chávez se ha referido a la necesidad de levantar el bloqueo de Estados Unidos al régimen cubano y ha reiterado en varias ocasiones su posición contraria a la tesis estadounidense de la ausencia de democracia interna en la isla. 
"Cuba y Venezuela dos banderas y una revolución" es una exclamación repetida varias veces por el presidente Chávez y que expresa la unión política y comercial que se ha convertido en un punto de referencia en América Latina. Cuba nunca tuvo un aliado en la región tan cercano. Fidel Castro fracasó en el apoyo a la lucha armada en la década de los sesenta, pero logró insertarse mucho más tarde en Venezuela por la vía electoral.

Pero el dinamismo de las relaciones entre Venezuela y Cuba no se limita al intercambio económico y comercial. El tema de la entente ideológica entre Venezuela y Cuba implica un debate en América Latina sobre la revolución y sobre la injerencia de esos países en los asuntos internos de terceros países (LANGE, 2002).

El Gobierno encabezado por el presidente Hugo Chávez ha considerado a la integración económica y comercial como un tema especial. La integración para el gobierno de Venezuela no se limita a plantear una alianza comercial, sino por el contrario, se entiende a la integración como algo global que se conecta con dos de los elementos básicos de la política que está ejecutando Caracas. Se trata de que a mediano plazo, esa integración esté fundamentada en bases no capitalistas, en el ejercicio de una democracia participativa, en la promoción de una economía que combine la propiedad estatal con propiedades sociales y cooperativas, y en la regulación y disminución de las inversiones extranjeras directas privadas. Es decir, el planteamiento venezolano es anti-capitalista y anti-estadounidense; por lo tanto, la integración para Venezuela escapa al modelo que se define en la OMC y que bajo el concepto de regionalismo abierto se ha venido planteando en América Latina y el Caribe (CORRALES, 2006).

Es por eso que no debe sorprender que Venezuela plantee el esquema de integración conocido como la Alternativa Bolivariana para las Américas (ALBA) que, de suyo, es un planteamiento diferente al ALCA y a los contenidos de los acuerdos comerciales y tratados de libre comercio que Washington está llevando a cabo con varios gobiernos en la región. Las ideas fundamentales del ALBA son: la integración no capitalista de los pueblos, la diversificación comercial, los convenios e inversiones intra-gubernamentales, un sistema de alianzas entre gobiernos progresistas y socialistas y la promoción de formas de propiedad alternativa a la propiedad privada (ROMERO, 2009).

Pero hay algo más: el debate político quedaría inconcluso si no se agregan otros dos temas: por una parte, el referido a las alianzas que Venezuela pueda promover y sostener en la dinámica interna de los países de la región para aumentar sus aliados y para impulsar los cambios políticos internos con base en el modelo venezolano actual: elecciones, asamblea constituyente, poder popular, economía social tutelada y financiada por el Estado, un desplazamiento de élites y una política internacional antiimperialista y bolivariana. Por otro lado, está presente el tema de la cooperación económica venezolana, tanto por la capacidad de compra del Estado (lo que origina, en el mayor de los casos, una asimetría en contra de Venezuela en las balanzas comerciales bilaterales), como por las donaciones e inversiones no retornables. Esto último plantea otra discusión importante: el tema de la proyección del rentismo venezolano interno al plano global, por la cooperación con gobiernos y actores no estatales (Véase la sección 5 de este artículo).

La política exterior de Venezuela se ha orientado hacia una dirección radical en el marco de la promoción del Socialismo del siglo XXI, cuestión que se ha acrecentado con más ahínco desde el año 2007. 
La respuesta de Estados Unidos ha sido moderada en cuanto a los cambios internos y externos observados en Venezuela desde los triunfos electorales presidenciales de Hugo Chávez en 1999, 2000 y 2006. De hecho, Venezuela ya no es vista como lo fue en le pasado, como un socio confiable, en función de la estabilidad democrática del país y de ser un seguro proveedor de petróleo. Ahora es otra cosa: no es la asociación de antaño, pero tampoco se ha llegado a la ruptura entre los dos países (KELLY, ROMERO, 2005).

En Bolivia, el presidente Chávez ha prometido, entre otras cosas, la creación de la empresa binacional venezolana-boliviana Petroandina con el encargo de buscar petróleo y de eventualmente explotarlo en el norte de Bolivia y ayudar al proyecto argentino-boliviano de la construcción de una planta de separación de líquido de gas, además del compromiso de crear la Organización de Países Productores y Exportadores de Gas del Sur (Opegasur).

Ecuador también se ha beneficiado de la ayuda de Venezuela y el presidente de ese país, Rafael Correa ha dicho en diversas ocasiones que acepta el "paquete ideológico" de Chávez. Ecuador es un país observador pero no es miembro pleno del ALBA (CORRALES, 2006).

Por otra parte, el Gobierno de Guyana presiona para que Venezuela renuncie a sus aspiraciones para que le sea devuelto el Territorio Esequibo. Como se sabe, Venezuela mantiene una reclamación reconocida por Gran Bretaña y Guyana sobre una parte del territorio guyanés que según Venezuela se le despojó en el siglo XIX. Como consecuencia de la firma del Acuerdo de Ginebra en 1966, Venezuela permitió la independencia de Guyana de Gran Bretaña sí le reconocía como válida su reclamación. Desde entonces se han llevado varios ciclos de negociación a fin de lograr un arreglo práctico (ROMERO, 2006).

Con la Unión Europea y con otros países europeos, Venezuela ha mantenido, por lo general, un modus vivendi en el cual han prevalecido los negocios y los intereses económicos por encima de las críticas políticas europeas en relación a la situación interna del país y algunos contrapunteos verbales, como el sostenido con el Jefe de Estado español y el presidente Chávez. Sin embargo, en el plano social europeo se han visto mayores debates y falta de consenso sobre lo que pasa en Venezuela. Están quienes apoyan al proceso bolivariano en la vida social del continente (partidos, sindicatos, académicos, organizaciones no gubernamentales), observándola como una revolución en marcha, y por el contrario están aquellos actores que critican el proceso y que están en desacuerdo con lo que pasa en Venezuela, incluyendo a ciudadanos de esos países que se han visto afectados por las políticas económicas del Gobierno de Chávez (LANGE, 2002).

En cuanto a Rusia, Belarús e Irán, el Gobierno y el oficialismo parten de la base que se está al borde de la revolución mundial en la cual Rusia juega el papel de país rector de un polo antiimperialista. El presidente Chávez cree que acercándose a Rusia adquiere un mayor prestigio mundial. En Irán, el presidente Chávez refrendó más de 100 acuerdos de naturaleza económica, destacándose la tesis iraní de que Venezuela pudiera ser un puente para las relaciones de ese país con el resto de América Latina y la certificación de un fondo financiero bilateral (CORRALES, 2006). 


\section{Los REsultados}

En el año 2007 se conoció un documento del gobierno del presidente Chávez titulado "Las líneas generales del Plan de Desarrollo Económico y Social de la Nación 2007-2013". Según el Plan, se pretende "neutralizar la acción del imperio fortaleciendo la solidaridad y la opinión pública de los movimientos sociales organizados" y como un objetivo más general, se establece la creación de una estrategia mundial "para la movilización de masas en apoyo al proceso revolucionario". De acuerdo con el Plan de Desarrollo, el Gobierno se plantea "una conducción multipolar de la política mundial" que se basa en "la creación de nuevos bloques de poder" (REY, 2007).

En este marco, la política exterior de Venezuela oscila entre tener unas buenas relaciones con todos los países, pero al mismo tiempo desarrolla su diplomacia social, en el marco de una dualidad conocida ya en experiencias revolucionarias anteriores.

Así, de esta manera, se ha abierto para el presidente Chávez un importante espacio político, junto con sus aliados y simpatizantes de su modelo alternativo a la economía liberal y la gobernabilidad democrática propuesta por Washington.

La proyección internacional del país ha jugado un papel fundamental en ese cambio sobre cuyas bondades y defectos, partidarios y opositores debaten constantemente. En este contexto, la diplomacia bolivariana ha sido manejada de igual manera que los asuntos domésticos. El enfoque amigo-enemigo de la política, el uso indiscriminado de la voluntad de la mayoría y el afán de promocionar un "paquete ideológico" populista radical, se han mezclado con tradiciones nacionales, en una oferta que ha contado con pocos obstáculos y con un poderoso verbo. Esto se ha complementado con múltiples compromisos con países, organizaciones, grupos sociales y personalidades que han hecho de Caracas, la nueva Meca revolucionaria.

El recibimiento a esas propuestas no confrontó muchos obstáculos. El fortalecimiento de una posición a favor de un mundo multipolar, el uso de la palanca petrolera como el norte de la cooperación internacional y el deslinde mediático de Estados Unidos fueron acciones aplaudidas por una galería de gobiernos progresistas, aparentemente neutrales o simplemente indiferentes que vieron con simpatía, las improvisaciones y propuestas de un régimen y de un líder como Hugo Chávez, quien aprovechó a su favor el relajamiento de la estructura internacional a comienzos del siglo XXI.

Cuando hablamos de ese relajamiento nos referimos a falta de consenso sobre la agenda global, la puesta en práctica de la política de seguridad estadounidense y de la línea antiterrorista y antinarcóticos de Washington, la cual obtuvo menos apoyo regional del esperado, más la presencia activa de otros poderes mundiales en América Latina, el ocaso del "Consenso de Washington" y del ALCA, y la ausencia de fórmulas de articulación comercial y económica sólidas, a la par del crecimiento sostenido de la economía internacional y de los precios del barril de petróleo. De modo que estos vientos a favor 
fortalecieron un espacio para una diplomacia que no encontró por muchos años límites reales a su gestión.

Pero no todo es tan fácil. En Estados Unidos se inicia una nueva administración que tendrá mayor cuidado con los temas de la defensa y la preservación de la democracia y de los derechos humanos en el hemisferio. En América Latina se observa cómo la ola izquierdista en la región comienza a retroceder y a presentar resultados negativos. Cuba ya no es un modelo a seguir; y la crisis económica internacional afecta la cotización de los precios del crudo a la vez que promueva tiempos de austeridad. China, Rusia e Irán no se han prestado a formar parte de una supuesta alianza estratégica sugerida por Caracas y se niegan a aceptar el "paquete ideológico" venezolano. Por si fuera poco, algunos gobiernos que no son necesariamente enemigos de la causa bolivariana, comienzan a preocuparse por el destino democrático venezolano, dados los actuales y renovados ímpetus reeleccionistas, estatistas y anti-capitalistas que se observan en las conductas oficiales de los gobernantes venezolanos (SHIFTER, 2005; ROMERO, 2009).

\section{El tema Del “RENTISMo” en la POLítica EXTERIOR}

El tema de la proyección del rentismo venezolano en el plano global, tiene que ver con la observación de cómo el gobierno del presidente Chávez controla la corriente rentística petrolera, a fin de promover su liderazgo continental y fundamentar su referencia global.

Es por ello que el mercado de rentas venezolano (favores, donaciones, traspasos, pagos a terceros, ayuda directa, condonaciones, financiamiento e inversiones sin tasa de retorno, etc.) se traslada al espacio global y es aprovechado por actores que manipulan la ayuda venezolana (renta geopolítica) para capturarla y tener acceso a ella (fundamentalmente las de carácter energética y financiera) y no por las vías comerciales (intercambio) y económicas (valor agregado).

Esta operación llamada de rent-seeking (y estudiada previamente en el contexto del colonialismo y los protectorados europeos) se está convirtiendo en un elemento especial en la concepción de integración que tiene el gobierno de Venezuela (OLSON, 2000; CORRALES, 2006; ROMERO, 2009).

El tema del rentismo ha ocupado un lugar importante en el estudio de las relaciones entre países. En el caso venezolano, hasta ahora se le había dado un tratamiento especial como fenómeno doméstico. Aunque en el pasado se pueden observar algunos rasgos de rentismo internacional por parte de Venezuela, es en el Gobierno de Hugo Chávez cuando esta modalidad se ha extendido. 


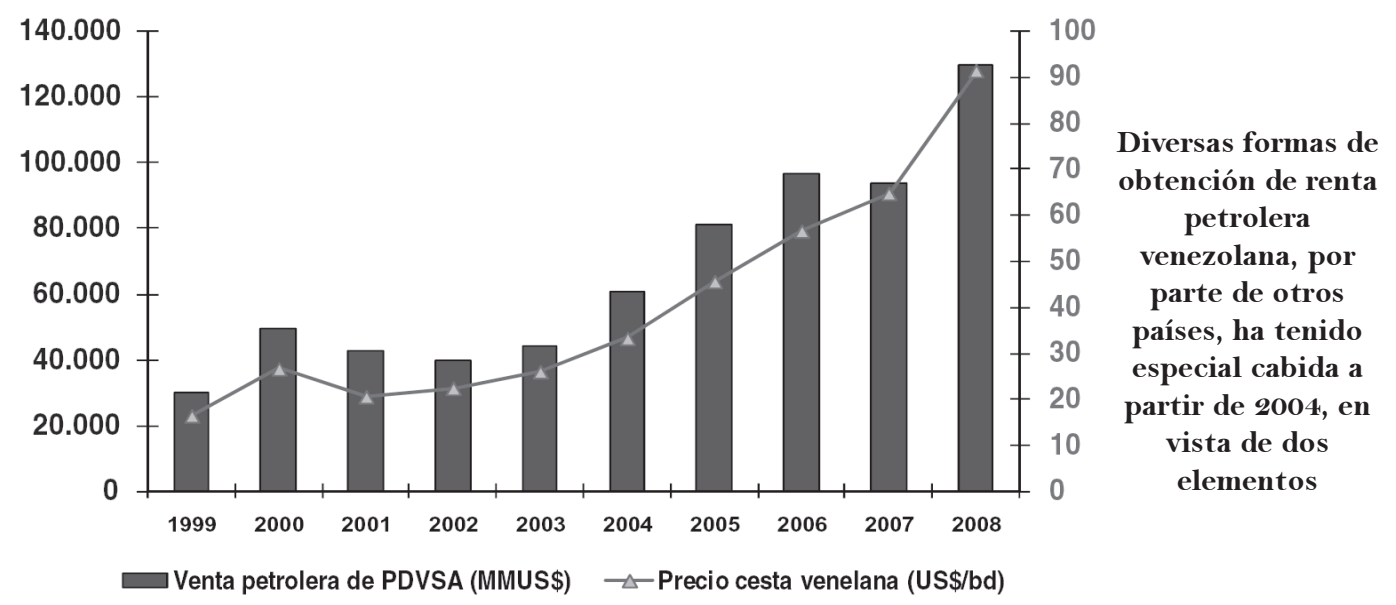

FUENTE: PDVSA, Ministerio de Economía y Finanzas, Cálculos propios.

1) el inicio de un boom en los precios internacionales del petróleo y por ende de los ingresos asociados con la exportación petrolera a partir de ese año (Ver Gráfica), y 2) la adopción de una estrategia internacional más agresiva por parte del gobierno del Presidente Hugo Chávez en cuanto a la construcción de alianzas regionales, con posterioridad al Referéndum Revocatorio Presidencial de 2004

Estas actuaciones no deben ser entendidas como actos improvisados o aislados, y de hecho se encuentran explícitamente previstos en los objetivos de instituciones tales como Petróleos de Venezuela (PDVSA) y el Banco Central de Venezuela. En ese sentido, la estrategia relacionada con la conformación de un mundo multipolar (dentro de la cual se inscriben las alianzas regionales) se entrecruza con los objetivos en materia energética, en la medida que la estrategia corporativa de la petrolera incluye el despliegue de una política empresarial de integración regional con las naciones de Suramérica, Centroamérica y el Caribe (PDVSA, 2004). Esta línea de acción se ha profundizado a medida que PDVSA ha avanzado en la suscripción de acuerdos internacionales con empresas petroleras estatales, orientados a la diversificación de mercados y al fortalecimiento de la integración energética regional (PDVSA, 2005).

Estas acciones se desarrollan en el marco de Petroamérica, instancia que es considerada como el habilitador geopolítico para el establecimiento de mecanismos de cooperación e integración, mediante la utilización de los recursos energéticos de las regiones del Caribe, Centroamérica y Suramérica. En Petroamérica confluyen Petrocaribe, Petrosur y Petroandina, y la agenda de acciones de cooperación que financia PDVSA se alinean con sus 3 objetivos: 1) Mitigar las asimetrías en el acceso a recursos energéticos; 2) Establecer mecanismos de cooperación e integración, sobre la base de la complementariedad, y 3 ) Impulsar la interconexión energética y la inversión conjunta en proyectos económicos, sociales y energéticos (PDVSA, 2007).

La estructura funcional que ha adoptado PDVSA responde a la activación de estas iniciativas con otros países. De hecho, un elemento característico es que se haya establecido como condición que las operaciones de Petrocaribe tienen que ser llevadas directamente por los estados, para lo cual exige la creación de empresas mixtas (entre las cuales se 
cuentan ALBA Petrocaribe en Belice, ALBANISA en Nicaragua o ALBA Petróleos en El Salvador) o se recurre a la figura de contratos de suministro.

Ese tipo de canal institucional es sólo uno de los caminos que siguen los fondos que ha destinado el gobierno venezolano a atender compromisos asumidos con otros países. En ese sentido, una expresión importante del tema del rentismo se encuentra en la adopción de estrategias extra-corporativas por parte de PDVSA. Un indicio importante sobre este tema se constata al revisar el listado de inversiones en refinerías y otros desarrollos en materia energética en otros países.

En el caso del Banco Central de Venezuela, esa entidad internaliza su rol para "impulsar el esbozo de una nueva arquitectura financiera regional, la cual es fundamental para lograr un sistema financiero regional estable, orientado a fortalecer el desarrollo endógeno, facilitar el financiamiento requerido para sostener en el mediano y largo plazo los objetivos de la integración y promover un papel más activo de la Unión de Naciones Suramericanas (Unasur) y del Mercado Común del Sur (Mercosur), dentro de los lineamientos y objetivos estratégicos de la política exterior del Estado venezolano" (BCV, 2008).

A partir del universo de transferencias, donaciones, inversiones y adquisiciones que ha realizado el gobierno del Presidente Chávez es posible considerar por convención cinco categorías, entre las cuales, los dos tipos de operación más significativos están relacionadas directamente con el negocio petrolero:

1) Estrategias PDVSA: las inversiones y aportes de la compañía estatal se corresponden con las estrategias de ampliación de capacidad de refinación del petróleo venezolano por parte de PDVSA, y las alianzas relacionadas con el tema energético. Este tipo de operaciones contiene el elemento rentista en la medida que Venezuela entrega recursos a proyectos que difícilmente se implementarían en otro caso, y al mismo tiempo introduce una injerencia de hecho, al asegurar la presencia de intereses venezolanos en los países de interés en el largo plazo. Estas inversiones se incluyen en convenios dentro de los cuales no se incorporan cláusulas para la explotación de esas facilidades por parte de PDVSA, ni arreglos en materia comercial o productiva, con lo cual se expresa la asimetría en contra de Venezuela.

2) Acuerdos de Cooperación Petrolera: incluye las ventas de petróleo con descuento asumidas bajo distintas modalidades. De acuerdo con PDVSA (2007), las ventas de petróleo a países con acuerdos de cooperación ascendieron a 203.900 barriles diarios en 2007. Estos volúmenes totalizan los aportes entregados por Petrocaribe (28\%); Acuerdo de Cooperación Energética de Caracas (12\%); Convenio Internacional de Cooperación (52\%) y Acuerdo de San José $(8 \%)^{(1)}$. Ese volumen representa alrededor del $10 \%$ de la exportación venezolana de petróleo. El seguimiento y ejecución de

\footnotetext{
(1) Estos cálculos se realizaron en función de los volúmenes efectivamente suministrados en 2007, que en la mayoría de los casos están muy por debajo de la Cuota correspondiente a cada país. Es necesario acotar que PDVSA (2007) no reporta los suministros acordados en el marco del Tratado Energético del ALBA dentro de las ventas bajo Convenios de Cooperación. Ese Tratado, suscrito en abril de 2007, establece el suministro del total de la demanda de hidrocarburos para Cuba, Bolivia, Nicaragua, Haití y Dominica, con el financiamiento del $50 \%$ de la factura. El restante $50 \%$ se destina a un fondo para la atención de proyectos de desarrollo productivo.
} 
estas iniciativas está centralizado en PDVSA América S.A., empresa creada en junio de 2006. Estos acuerdos complementan lo que fue el Acuerdo de San José, pero prevén condiciones mucho más ventajosas para los países firmantes, cuya máxima expresión está en las entregas de petróleo a Cuba y los acuerdos suscritos en el marco del ALBA.

3) Donaciones o Aportes Directos: agrupa las transferencias, ayudas en efectivo o en especies que el gobierno venezolano ha realizado a otros países, ya sea en ejecución de convenios comerciales o de cooperación, la condonación de deudas o la atención a situaciones puntuales. Dentro de este grupo de expresiones de rentismo se identifican elementos de muy diversa naturaleza que abarcan compra de viviendas, construcción de autopistas y otras obras de infraestructura, hasta la atención de temas humanitarios. Un caso particular lo representa la adquisición de la empresa estatal y cooperativa Sancor, empresa argentina que fue rescatada por el gobierno venezolano durante la crisis económica de ese país del mes de septiembre de 2006, con un aporte de 135MMUS\$, sin que Venezuela obtuviera como contraprestación la recepción del total del volumen producido por esa empresa.

4) Intercambios: dentro de esta categoría se contabilizan los aportes en petróleo hechos por Venezuela que han tenido contraprestación en bienes y servicios suministrados por los destinatarios. Esa contrapartida constituye un matiz respecto a los casos de rentismo previamente considerados. Un caso especial es el de las relaciones con Cuba, en donde se traen de ese país recursos humanos cuyo costo es pagado con el envío de petróleo venezolano a la isla.

5) Operaciones de financiamiento: incluye la compra de títulos de deuda y otras operaciones que implican la participación en el financiamiento de otros gobiernos, con una aproximación poco tradicional para la incursión de un gobierno como el venezolano en mercados financieros internacionales.

Las contribuciones que el gobierno venezolano ha comprometido y/o realizado hacia otros países han totalizado 36.406 US \$ (acumulados desde 1999 hasta febrero de 2009). A juzgar por la diversidad de proyectos que componen ese total, puede sugerirse que la renta se utiliza no sólo para avanzar en estrategias de control político y de formación de alianzas, sino que Venezuela, especialmente, por intermedio de PDVSA, aparece como una suerte de organismo multilateral, que matiza la naturaleza de sus relaciones con América Latina y el Caribe.

De acuerdo con Zerpa, el Presidente Chávez ha señalado que la cooperación energética venezolana asciende a unos 1.600 Millones US\$ al año, por lo que supera en montos a la ofrecida por el gobierno de Estados Unidos, el donante de ayudas más grande del mundo. Según datos de la ONG estadounidense, Center for International Policy, el total de esa cooperación es cercano a la asistencia antidrogas y de desarrollo estadounidense en América Latina para 2007, que fue de 1.900 Millones US\$ (ZERPA, 2007).

Los montos acumulados en cada una de las categorías descritas, a febrero de 2009, se recogen en el Cuadro 1. 


\section{Cuadro 1}

\begin{tabular}{|l|c|c|}
\hline \multicolumn{1}{|c|}{ Categorías } & $\begin{array}{c}\text { Total acumulado } \\
\text { (en US } \$ \text { ) }\end{array}$ & $\begin{array}{c}\text { Participación \% } \\
\text { dentro del total }\end{array}$ \\
\hline Estrategias PDVSA & 11.502 & $31,6 \%$ \\
\hline Acuerdos de cooperación petrolera & 14.562 & $39,9 \%$ \\
\hline Donaciones o aportes directos & 2.108 & $5,8 \%$ \\
\hline Intercambios & 0.740 & $2,0 \%$ \\
\hline Operaciones de financiamiento & 7.504 & $20,6 \%$ \\
\hline TOTAL GENERAL & 36.406 & \\
\hline
\end{tabular}

FUENTES: PDVSA; Ministerio del Poder Popular para Economía y Finanzas; Ministerio del Poder Popular para las Relaciones Exteriores; Banco Central de Venezuela; Bandes.

De todo ese universo, los países que más recursos han percibido son Cuba (35.7\%), Argentina (25,2\%), Ecuador (13.9\%), Nicaragua (8.4\%), Brasil (6.0\%), Uruguay (2.7\%) y Bolivia (2.4\%). El resto de los países beneficiados incluye a Paraguay, Honduras, República Dominicana, Dominica, Haití, Jamaica, El Salvador, Guyana y Estados Unidos y el caso especial de Puerto Rico.

Los compromisos asociados con la estrategia de erigir nuevos anclajes de PDVSA a través de la inversión en sectores energéticos de otros países, han tenido como principales destinos a Ecuador (Refinería de Manabí, 5.00o MMUS\$), Nicaragua (Refinería El Supremo Sueño de Bolívar, 2.50o MMUS\$), Brasil (Pernambuco — Estudios Previos, 50 MMUS\$), Uruguay (Refinería La Teja, 600 MMUS\$); Argentina (Refinería Ghasa y Planta de Regasificación, 500 MMUS\$); Cuba (Refinería Cienfuegos, 166 MMUS\$); Paraguay (Refinería de Villa Elisa, 100 MMUS\$) y Jamaica (Refinería Petrojam, 87 MMUS\$).

En materia de cooperación petrolera, Cuba es el país que ha recibido más recursos, ya que los 7 años de suministro de petróleo que se han estimado ascienden a 12.348 MMUS\$, monto que representa el $85 \%$ del total de la cooperación petrolera de Venezuela, y el $34 \%$ del total de todos los recursos analizados.

En el caso de las Donaciones o Aportes Directos, Bolivia ha recibido un 25\% del total considerado, y le siguen Bielorrusia (300 MMUS\$, equivalente al 15\%); Cuba (10\%); República Dominicana, Dominica, Haití y Nicaragua (con $8 \%$ aproximadamente, cada uno). El detalle se presenta en el Cuadro 2. 


\section{Cuadro 2}

\begin{tabular}{|c|c|c|}
\hline PAIS & CONCEPTO DEL APORTE & $\begin{array}{l}\text { MONTO } \\
\text { (MMUSS) }\end{array}$ \\
\hline \multirow{8}{*}{ Cuba } & Construcción de 150 casas & 2.000 .000 \\
\hline & Proyecto de Electrificación & 20.000 .000 \\
\hline & Proyecto de Desarrollo Endógeno Pinar del Río & 5.862 .000 \\
\hline & Sueldo de 400 dólares mensuales a cada médico cubano & 96.000 .000 \\
\hline & Financiamiento para la compra de insumos para construcción & 10.000 .000 \\
\hline & Financiamiento para la compra de materiales de seguridad & 20.000 .000 \\
\hline & Línea de crédito para el sector turismo & 10.000 .000 \\
\hline & Construcción de obras sociales en Cienfuegos & 30.400 .000 \\
\hline \multirow{2}{*}{ Dominica } & Construcción de un nuevo aeropuerto & 10.000 .000 \\
\hline & Construcción de barreras de protección marina, viviendas y créditos & 150.000 .000 \\
\hline \multirow{3}{*}{ Estados Unidos } & Financiamiento de la limpieza del Río Hudson & 100.000 \\
\hline & Subsidio a combustible para calefacción & 10.000 .000 \\
\hline & CITGO - Donación afectados por Katrina & 5.000 .000 \\
\hline Jamaica & Préstamo para la construcción de "Autopista 2000" & 30.000 .000 \\
\hline \multirow{2}{*}{$\begin{array}{l}\text { Rep. } \\
\text { Dominicana }\end{array}$} & Préstamo obras de infraestructura & 156.400 .000 \\
\hline & Compra de 500 viviendas & 7.500 .000 \\
\hline \multirow{3}{*}{ Haití } & Adquisición de equipos, construcción de viviendas & 20.000 .000 \\
\hline & Proyectos de generación eléctrica & 70.000 .000 \\
\hline & Capacidad aeroportuaria y recolección de basura & 60.000 .000 \\
\hline \multirow{3}{*}{ Argentina } & Reparación de tres buques - Argentina & 6.450 .000 \\
\hline & Construcción de dos buques - Argentina & 112.000 .000 \\
\hline & Compra de planta de productos Lácteos SANCOR & 135.000 .000 \\
\hline \multirow{4}{*}{ Nicaragua } & Programas de salud, educación, agricultura, energía y exportaciones & 90.000 .000 \\
\hline & BANDES - Proyectos sociales & 10.000 .000 \\
\hline & 32 Plantas Eléctricas & 32.000 .000 \\
\hline & Absolución de la deuda & 26.200 .000 \\
\hline \multirow{8}{*}{ Bolivia } & Donación para ayudar a Bolivia (Fondosur) & 30.000 .000 \\
\hline & Helicópteros Súper Pumas & 31.000 .000 \\
\hline & Financiamiento de 5 mil becas de estudio & 16.700 .000 \\
\hline & Construcción de una autopista & 300.000 .000 \\
\hline & Ayuda para fábrica de casas & 80.000 .000 \\
\hline & Canal de Televisión & 5.000 .000 \\
\hline & Construcción stadium de futbol & 4.000 .000 \\
\hline & Aporte para construcción de infraestructura de las Fuerzas Armadas & 30.000 .000 \\
\hline Ecuador & Apertura de Bandes & 10.000 .000 \\
\hline \multirow{4}{*}{ Uruguay } & Línea de crédito para emprendimientos & 3.000 .000 \\
\hline & Préstamo para equipar y remodelar el Hospital Universitario & 17.000 .000 \\
\hline & Instituto Nacional del Cáncer & 3.000 .000 \\
\hline & Créditos para recuperar empresas & 5.000 .000 \\
\hline Brasil & Escola de Samba Vila Isabel & 1.000 .000 \\
\hline
\end{tabular}


Venezuela: Política Exterior y Rentismo

\begin{tabular}{|llr|}
\hline \multicolumn{1}{|c}{ PAIS } & \multicolumn{1}{c|}{ CONCEPTO DEL APORTE } & $\begin{array}{c}\text { MONTO } \\
\text { (MMUS\$) }\end{array}$ \\
\hline Bielorrusia & Ayuda a la cancelación de la deuda externa con Rusia & 300.000 .000 \\
\hline África & Donación a Países afectados por la sequía & 3.000 .000 \\
\hline Guyana & Condonación y pago de deuda & 24.500 .000 \\
\hline \multirow{2}{*}{ Honduras } & Condonación Deuda Petrocaribe & 30.000 .000 \\
& Donación de Tractores y maquinaria agrícola & 82.000 .000 \\
& Programa de ahorro de energía (donación de bombillos) & 7.000 .000 \\
\hline
\end{tabular}

FUENTE: PDVSA; Ministerio del Poder Popular para las Relaciones Exteriores; El Nacional; El Universal; Aporrea.org; Granma; nvnoticias.com.ar; El Clarín; Diario La Voz; El Heraldohn; Larepublica.com.uy; Minci.gob.ve; Diario Co Latino; Agencia Bolivariana de Noticias; Centroamerica; Diario Vea; El Carabobeño.

La actividad relacionada con el financiamiento, la posición más importante como receptor la ocupa Argentina, pues las operaciones de compra de Deuda y de títulos de ese país ascienden a 6.961 MM US\$, que implica el 92\% del total de la actividad de financiamiento y el $19 \%$ de todo el universo de las erogaciones en rentismo/control que se han considerado.

La relevancia de los diferentes destinatarios de estas transferencias y/o erogaciones no se corresponde con la composición de las relaciones comerciales de Venezuela. De hecho, en el año 2007 los seis principales socios comerciales de Venezuela según la procedencia de las importaciones fueron Estados Unidos (26\%), Colombia (14\%), Brasil (10\%), China (8\%), México (5\%) y Panamá (5\%). En consecuencia, los flujos de comercio no explican los destinos y las relaciones construidas por medio de las erogaciones que se han señalado, cuya motivación se corresponde con estrategias relacionadas con la integración política regional y el reforzamiento de las relaciones con el Sur.

Este boom de rentismo venezolano, del cual han sacado provecho unos cuantos países en los últimos años, contiene sin embargo, algunos riesgos para su continuidad y sus resultados esperados. La caída del sistema financiero internacional y la recesión mundial (con el consecuente desplome de los precios del petróleo), cuyo comienzo se ubica en septiembre de 2008, tiene repercusiones directas dentro de estas líneas de acción. De hecho, en noviembre de 2008 PDVSA anunció que "están en evaluación las inversiones internacionales de las refinerías en Ecuador y Nicaragua, donde estamos pidiendo buscar financiamiento y disminuir la participación accionaria" (DEL PINO, 2008). Asimismo, se ha señalado que la Refinería de Pernambuco pasaría a ser una iniciativa exclusiva de Petrobrás y que el proyectado gasoducto del Sur estará archivado por un buen tiempo.

La continuidad de estos despliegues pudiera estar comprometida en vista del comportamiento del mercado petrolero y la reducción de ingresos venezolanos. Sin embargo, hasta la fecha, el rentismo venezolano ha resultado en una fuente generosa y visible para la proyección de Venezuela en la gran mayoría de los países de América Latina.

\section{Conclusiones}

En diversas ocasiones y por diversos medios, Venezuela ha llamado recientemente la atención de los estudiosos de América Latina. Para algunos autores este es un caso de 
regresión democrática, para otros, se está en la presencia de una profundización democrática. Para un tercer grupo, este es un caso de populismo "duro" con sus elementos principales: la referencia sostenida al pueblo-victima capaz de desarrollar un resentimiento social y movilizarse, la idea de cambio, la existencia de un líder carismático e hiperpersonalizado y en relación directa con las masas, una política económica estatista, clientelista y nacionalista y una conducta antiimperialista (TAGUIEFF, 2007; WEYLAND, 2003). Sobre este tema no hay un consenso posible; pero en lo que si se puede estar de acuerdo, es que ha habido un importante cambio en la Venezuela actual, en donde un sistema político que se creía estable dio paso a otro sistema político basado en otras ideas, en otros instrumentos y bajo otra dirección.

El análisis politológico ha tomado en cuenta estos cambios, lo cual ha obligado a realizar un esfuerzo intelectual que tiene una doble facturización: por una parte, se trata de identificar unos datos relevantes para analizar la extensión y la profundidad de esas transformaciones. Pero también se trata de aplicar una nueva perspectiva que supere el paradigma dominante que por más de treinta años observó el caso venezolano como sui generis y difícil de incluir en las clasificaciones de la política comparada sobre los regimenes políticos.

Es cierto que ha habido intentos de analizar el proceso a través de la sociología electoral, del constitucionalismo, de la teoría de la dependencia, y desde luego, desde algunas perspectivas ideológicas como el liberalismo y el marxismo. Pero en todos estos casos, no habido una configuración general y comparada que permita observar como un todo, lo que nosotros denominamos una nueva Politeia (ROMERO, 2006).

Este orden político, cuya decisión es trasladarlo paulatinamente de una democracia puntofijista a una experiencia socialista, presenta algunas características similares al antiguo régimen y por supuesto algunos elementos novedosos. De lo anterior se tienen el presidencialismo, el poder estatal, el control de los sectores populares, la utilización del Gasto Público como palanca de desarrollo, el uso indiscriminado de la renta petrolera como fuente central del ingreso nacional y la presencia de una débil institucionalidad. De lo nuevo, se tiene el poder del presidente Chávez sobre el país como "primus-inter-pares" (lo fueron los partidos dominantes en el pasado), la orientación estatista-socialista de la economía (antes hubo una economía mixta de orientación capitalista y los intentos de crear una democracia directa (antes hubo una democracia representativa).

De hecho, estamos en la presencia de un Estado que genera un alto grado de incertidumbre, dado su carácter cuàsi-monopólico de colector de la renta petrolera, y que no contribuye a promocionar, pero sí a reducir, los ingresos de la sociedad civil (OLSON, 2000).

Particular atención se debe prestar al impacto del rentismo que ha establecido lazos de diversa índole con países que se insertan en nuevos mecanismos de alianzas suscritas dentro de las estrategias de creación de un mundo multipolar, de consolidar un nuevo esquema de alianzas regionales y de convertir a Venezuela en una potencia energética. El rentismo ha sido significativo en alcance y en magnitud, por lo que el fin del boom petrolero de 2003-2008 pondrá a prueba la efectividad de la generosidad del gobierno de Hugo Chávez en cuanto a modificar las alianzas y mecanismos de cooperación entre los países de América Latina. 
Estamos analizando entonces un proceso de transición que va de una democracia pactada a una post-democracia y a un autoritarismo electoral Si esto fuera así, tendríamos ante nuestros ojos un caso poco frecuente y poco estudiado en la política comparada, la cual más bien, le ha prestado una mayor intención a los procesos de transición política que van de un espacio político autoritario a uno de orientación democrática (KORNBLITH, 2007; CORRALES, 2006).

Dentro de esta dirección y transcurridos diez años del liderazgo de Hugo Chávez en Venezuela, la política exterior del país puede considerarse como un "reflejo" de las fortalezas y debilidades de un proceso que rompió con el pasado, y que hoy se estabiliza bajo coordenadas diferentes. Posiciones radicales sobre temas de la agenda, como lo son los fenómenos intermésticos, la injerencia interna, el control civil sobre los temas de seguridad, el terrorismo, los derechos humanos, la cooperación y la democracia, le permiten al gobierno de Venezuela marcar distancia con los consensos alcanzados y proponer un paquete ideológico diferente que no sólo se quiere aplicar en la dinámica internacional del país sino que también se quiere imponer como un modelo a seguir por el resto de las naciones latinoamericanas y caribeñas.

En segundo término, se ha desarrollado un discurso radical en la política exterior en donde se aspira aun mundo multipolar, se entiende a Venezuela bajo la amenaza permanente de un ataque militar de Estados Unidos y de una política de desestabilización por parte de ese país, se promocionan sectores sociales alternativos en el mundo, se cambia la política de alianzas, se promociona un acercamiento a "países problema", se reinterpreta el tema de la cooperación internacional promoviéndose lo que definimos como "rentismo global". Así no es de extrañar que "el Gobierno interprete que el país tiene el derecho y la habilidad para transformar en el mundo de acuerdo a su propia imagen" (ETZIONI, 2007). En relación a lo anterior, el presidente Chávez dijo que "Venezuela quiere seguir y va a seguir luchando por un mundo de igualdad, de libertad y de justicia, donde no haya más imperialismo, un mundo donde se respete la soberanía de las naciones, la libertad de los pueblos, un mundo de paz pues, para que haya paz tiene que haber justicia" (CHÁVEZ, 2007-4).

En esta nueva configuración internacional del país, se abren múltiples posibilidades a la investigación, como el de analizar las visiones de mundo y los elementos discursivos que de algún modo conforma un imaginario político, que a su vez genera una práctica diplomática que como un todo propone un modelo de conducta internacional que pone en discusión temas teóricos, como el alcance de la autonomía internacional de un país, el rol de los países intermedios en la estructura mundial actual, el papel que juegan los recursos naturales como instrumentos de política internacional, el uso de un lenguaje radical, las consecuencias del rentismo internacional para la independencia de esos países, el desarrollo de un liderazgo internacional de Venezuela y las posibilidades de un mundo multipolar. Desde el punto de vista de la práctica política, destacan el desarrollo de la alianza cubano-venezolana, la red latinoamericana de gobiernos y movimientos afines a la propuesta venezolana, la concreción del ALBA, las relaciones especiales con países como Cuba, Irán, Rusia, China y otros de menor importancia como Vietnam y Belarús.

Esto lleva a un punto interesante. Venezuela había tenido un importante papel en el funcionamiento de alianzas políticas y económicas con parte de países extra-continentales, 
tanto en plano bilateral como en el plano multilateral. Recuérdese el papel que jugó Venezuela en la creación de la OPEP, en el Grupo e los 77 y en el Grupo de los Quince, coaliciones políticas que se han desarrollado en torno al sistema de Naciones Unidas. El país también ha participado como observador y luego como miembro pleno del Movimiento de Países No Alineados y desde el año 2003, en el llamado Grupo de los 20, en el seno de la $\mathrm{OMC}$.

Pero el gobierno de Hugo Chávez se siente incómodo y se ha venido separando de esos procesos multilaterales, al percibirlos como muy neutrales en relación a los temas de la lucha antiimperialista y el planteamiento radical en las relaciones internacionales. Es por ello que se prefieren unas relaciones especiales con países como Irán y Cuba, fortalecer el ALBA, y promover un nuevo multilateralismo no liberal, lo que a la larga lleve al Gobierno de Chávez a tener relaciones continentales en el marco de la identidad bolivariana y simultáneamente a tener relaciones extra-continentales bajo el signo del antiimperialismo (HURRELL, 2006).

En este contexto, y viéndolo desde una perspectiva a largo plazo, la conducta de Venezuela en el plano internacional consistiría en un importante caso en donde se aspira a influir mundialmente, con el interés de captar otros actores, como una forma de resistencia a la globalización y en contra de la hegemonía estadounidense, a fin de mermar su poder (HURRELL, 2007).

$\mathrm{Al}$ ensayar algunos escenarios en un contexto estatal, multilateral y transnacional con diversas interrogantes, se tiene que a un corto plazo, la tendencia va a ser que el Gobierno del presidente Chávez siga insistiendo en su política hiper-activa y a su vez ambigua, en su actuación internacional, enfocándose en materia de economía internacional hacia un patrón de especialización basado en la explotación de los recursos naturales y a la vez enfrentado el tema de la injerencia en los asuntos internos de otros países de la región, incluyendo a su propios aliados (VERA, 2006).

Para bien o para mal, el presidente Chávez sigue gobernando en Venezuela y sigue enviando señales contradictorias a un mundo tan complejo que no termina de comprender lo que pasa en Venezuela, que le atribuye al presidente Chávez "de predicar un socialismo lubricado con petróleo" y que no deja de sospechar que ya mucho de esto ocurrió previamente en América Latina (ROSENBERG, 2007).

\section{REFERÊNCIAS BIBLIOGRÁFICAS}

\section{Libros}

ÁLVAREZ, Ángel (coord.). El sistema político venezolano: crisis y transformaciones. Caracas: Instituto de Estudios Políticos, Universidad Central de Venezuela, 1997.

CARDOZO, Elsa. Cuarenta años después: la política exterior que tuvimos y la que necesitamos. Revista Venezolana de Análisis de Coyuntura, Caracas: FACES-UCV, v. IV, n. 1, p. 43-63, ene./jun. 1998.

. La política exterior de Venezuela 1999-2002. Ni del Estado, ni para la sociedad. Revista de la Facultad de Ciencias Jurídicas y Políticas, Universidad Central de Venezuela, n. 24, p. 165-186, mayo/ago. 2006. 
CENTRO DE INVESTIGACIONES ECONÓMICAS (CIECA). Gasto Público Anunciado y Realizado por el Gobierno Venezolano - Refinerías. Acumulado al 12.9.2008.

COPPEDGE, Michael. Venezuela: soberanía popular versus democracia liberal. En: DOMÍNGUEZ, Jorge; SHIFTER, Michael (eds). Construcción de gobernabilidad democrática en América Latina. México: Fondo de Cultura Económica, 2005.

CORRALES, Javier. Hugo Boss. How Chavez is refashioning dictatorship for a democratic age. Foreign Policy, p. 32-40, jan./feb. 2006.

DIAMINT, Rut. Cuestiones militares en América Latina. En: DOMÍNGUEZ, Jorge; SHIFTER, Michael (eds.). Construcción de gobernabilidad democrática en América Latina. México: Fondo de Cultura Económica, 2005.

DOMINGUEZ, Jorge; SHIFTER, Michael (eds.). Construcción de gobernabilidad democrática en América Latina. México: Fondo de Cultura Económica, 2005.

ETZIONI, Amitai. Security first. For a muscular, moral foreign policy. New Haven: Yale University, 2007.

HURRELL, Andrew. Hegemony, liberalism and global order. What space for would-be great powers? International Affairs, v. 82, p. 1-19, 2006.

. One world? Many worlds? The place of regions in the study of international society. International Affairs, v. 83, n. I, p. 127-146, 2007.

INSTITUTO DE ESTUDIOS POLÍTICOS. La agenda de la política exterior. Caracas: UCV.

KARL, Terry Lynn. The paradox of plenty. Oil booms and petro-states. Berkeley: University of California, 1997.

KELLY, Janet; ROMERO, Carlos A. Venezuela y Estados Unidos. Coincidencias y conflictos. Epílogo. Caracas: IESA-Libros del Nacional, Colección Minerva, 2005. p. 201-212: 208.

KORNBLITH, Miriam. Crisis y transformación del sistema político: nuevas reglas de juego. En: ÁLVAREZ, Ángel (coord.). El sistema político venezolano: crisis y transformaciones. Caracas: Instituto de Estudios Políticos, Universidad Central de Venezuela, 1997.

LANGUE, Frédérique. Hugo Chávez et le Venezuela. Un action politique au Pays de Bolivar. Paris: L’Harmattan. 2002.

LEVINE, Daniel. Conflict and political change in Venezuela. Princeton: Princeton University, 1973.

MICHELENA, José Agustín Silva. Exploraciones en análisis y síntesis. Caracas: UCV, 1967.

NAIM, Moisés. La Internacionalización de Hugo Chávez. In: KELLY, Janet; ROMERO, Carlos A. Venezuela y Estados Unidos. Coincidencias y conflictos. Epílogo. Caracas: IESA-Libros del Nacional, Colección Minerva, 2005.

NAIM, Moisés; PIÑANGO Ramón. El caso Venezuela. Una ilusión de Armonía. Caracas: IESA, 1984.

OLSON, Mancur. Dictatorship, democracy and development. En: OLSON, Mancur; KAHKONEN, Satu (eds.). A not-so dismal science. A broader-view of economies and societies. Oxford: Oxford University, 2000.

OLSON, Mancur; KAHKONEN, Satu (eds.). A not-so dismal science. A broader-view of economies and societies. Oxford: Oxford University, 2000. 
REY, Juan Carlos. El futuro de la democracia en Venezuela. Caracas: Serie Estudios-Colección Idea, 1989.

- La democracia venezolana y la crisis del sistema populista de conciliación. Madrid: Centro de Estudios Constitucionales, 1991.

. Sobre los conceptos de Constitución y poder constituyente en el proyecto político de Hugo Chávez. Analítica Premium.com, feb. 2007.

. El sistema político venezolano y los problemas de su política exterior. La Agenda de la Política Exterior. Caracas: UCV, Instituto de Estudios Políticos, 1983.

ROMERO, Carlos A. Jugando con el globo. La política exterior de Hugo Chávez. Caracas: Ediciones B, 2006.

. Una diplomacia sin límites. PODER. Caracas: Edición 1, p. 44-46, feb. 2009.

ROSENBERG, Tina. Oil meets socialism in Venezuela. The Internacional Herald Tribune, nov. 3, 2007. Disponible en: <www.iht.com>.

SHIFTER, Michael. Moderación de las expectativas de la democracia. En: DOMÍNGUEZ, Jorge; SHIFTER, Michael (eds.). Construcción de gobernabilidad democrática en América Latina. México: Fondo de Cultura Económica, 2005.

TAGUIEFF, Pierre-André. L' IIlussion Populiste. Essai sur les démagogies de l’âge démocratique. Paris: Champs-Flammarion, 2007.

VERA, Leonardo. El nuevo modelo de desarrollo productivo: sus bases, limites y contradicciones. Disponible en: <http://www.analíticapremium.com> Acesso em: dic. 2006.

WEYLAND, Kart. Economic voting reconsidered: crisis and charisma in the election of Hugo Chavez. Comparative Political Studies, v. 36, n 7, p. 822-848, sep. 2003.

\section{Publicaciones oficiales}

BANCO CENTRAL DE VENEZUELA. BCV. Informe Anual 2007.

Mensaje de Fin de año del Presidente del Banco Central de Venezuela, diciembre de 2008.

CHÁ VEZ, Hugo. Memoria y cuenta del ejercicio gubernamental 2006. Disponible em: <www.mre.gov.ve> Acesso em: 13.1.07.

. Acto de juramentación de Hugo Chávez Frías como Presidente de la Republica Bolivariana de Venezuela, periodo 2007-2013. Ministerio del Poder Popular para las Relaciones Exteriores, 2007.

- (2007-8): Anteproyecto de Reforma Constitucional presentado por el Presidente de la República Bolivariana de Venezuela, Hugo Chávez Frías, Caracas, 15 de agosto de 2007 (mimeo).

EMBAJADA DE LA REPUBLICA BOLIVARIANA DE VENEZUELA, MONTEVIDEO. Acuerdos suscritos en materia de Desarrollo Social. 14 de junio de 2007.

GOBIERNO BOLIVARIANO DE VENEZUELA. 9 años de Revolución. Aspectos Económicos. 2008.

MADURO, Nicolás. Discurso del Canciller de Venezuela Nicolás Maduro en la ONU. 12.10.2007. En: Juventud Rebelde, Diario de la Juventud Cubana, La Habana, 2007.

MINISTERIO DEL PODER POPULAR PARA LAS RELACIONES EXTERIORES. Convenio de cooperación para el desarrollo social entre la República Bolivariana de Venezuela y la República Argentina, 11 de agosto de 2005.

60 
MINISTERIO DEL PODER POPULAR PARA LAS RELACIONES EXTERIORES. Acuerdo de Cooperación Energética de Caracas.

PDVSA. Gestión y resultados 2004.

. Gestión y resultados 2005.

. Información financiera y operacional 2001-2003.

. Información financiera y operacional al 31 de diciembre de 2003.

Información financiera y operacional, al 31 de diciembre de 2007.

de 2008

Informe operacional y financiero, período de nueve (9) meses terminado el 30 de septiembre

Pluripolaridad a través de la Energía, 2006.

\section{Borradores y declaraciones de prensa}

CHAVEZ, Hugo. Chávez: declaraciones sobre los EEUU. Disponible em: <www.eluniversal.com> Acesso em: 5.12.06.

. Declaraciones sobre el presidente Bush. El Nacional, 2.2.07: A/2.

. Declaraciones sobre la posibilidad de una CAN Bolivariana. Disponible en: <www. financiero.com/noticias> Acesso em: 7.10.07.

Declaraciones sobre la posibilidad de una Confederación de Repúblicas suramericanas. Disponible em: <www.el> universal Acesso em: 14.10.07.

Declaraciones sobre una Confederación de Repúblicas entre Venezuela y Cuba. Chávez. Disponible en: <www.aporrea.org> Acesso em: 14.10.07.

PINO, Elogio del. Declaraciones PDVSA revisa la construcción de refinería en Nicaragua. Caracas: La Voz.com. 28.11.08.

KORNBLITH, Miriam. Venezuela. De la democracia representativa al socialismo del siglo XXI. Borrador, oct. 2007.

MADURO, Nicolás. Declaraciones le canciller de la Republica Bolivariana de Venezuela. Disponible em: <www.el-nacional> Acesso em: 26.10.2007.

REYES, Tais. Plan de desarrollo 2007-2013 propone reforzar "eje Cuba-Venezuela-Bolivia”. El Universal, 7.10.2007.

ZERPA, Fabiola. Diplomacia energética de Venezuela se orienta hacia la integración y la Multipolaridad. El Nacional, 20 de mayo de 2007. Disponible en: <http://www.embaven.org.co>. 